\title{
PERANCANGAN GEDUNG KESENIAN TARI DAN PEWAYANGAN KOTA BEKASI MELALUI PENDEKATAN ARSITEKTUR EKOLOGI
}

\author{
Nadia Sabrina ${ }^{1)}$, Mieke Choandi $^{21}$ \\ 1)Program Studi S1 Arsitektur, Fakultas Teknik, Universitas Tarumanagara, nadia.31517203@stu.untar.ac.id \\ 2) Program Studi S1 Arsitektur, Fakultas Teknik, Universitas Tarumanagara, miekec@ft.untar.ac.id
}

\begin{abstract}
Abstrak
Perkembangan zaman terus terjadi sehingga semakin tergerus budaya yang dianut, hal ini mengakibatkan kita lupa akan pentingnya budaya, spiritual, etika dan moral. Khususnya pada Kota Bekasi yang merupakan kota peri-urban dimana terletak antara pusat kota dan desa. Tari dan pewayangan Kota Bekasi cukup dikenal sebagai budaya setempat namun, terus mengalami kepunahan. Hal ini berkaitan langsung dengan mulai terlupakannya budaya Kota Bekasi mengakibatkan hilangnya identitas Kota Bekasi. Pembangunan suatu fungsi sebagai pemenuhan kebutuhan manusia haruslah mempertimbangkan lingkungan alam sekitar dan hubungan timbal balik antar manusia dan lingkungannya. Maka dari itu, Penggunaan prinsip arsitektur ekologi perlu diterapkan dalam bangunan. Tujuan proyek sebagai upaya pelestarian kesenian tari dan pewayangan Budaya Kota Bekasi. Metode perancangan menggunakan prinsip arsitektur ekologi. Konsep Source ZEB dengan memanfaatkan sinar matahari sebagai sumber energi bangunan dan menerapkan sistem Grey-water recycling dan penampungan air hujan. Massa berbentuk melengkung agar bangunan lebih dinamis. Massa di buat berundak untuk pengudaraan dan pencahayaan alami dapat masuk sehingga pemanfaatan sumber daya alam terbarui dapat maksimal.
\end{abstract}

Kata kunci: Arsitektur Ekologi; Balai Kesenian; Ekologi

\begin{abstract}
As times goes by, the culture adopted became more eroded, this causes us to forget the importance of culture, spirituality, ethics and morals. Especially in the city of Bekasi which is a peri-urban city which is located between the city and the village. Traditional dance and puppetry are well known as local culture, however, it is now on a verge of an extinction. it relates to forgotten culture of the City of Bekasi resulting in the loss of the identity of the City of Bekasi. The development of a function as a fulfillment of human needs must consider the surrounding natural environment and the reciprocal relationship between humans and their environment. Therefore, the use of ecological architectural principles needs to be applied. The purpose of the project is to preserve the arts of dance and puppet culture in the City of Bekasi. The design method uses the principles of ecological architecture. Source ZEB concept by utilizing sunlight as a building energy source and applying a system of Grey-water recycling and rainwater collection. The mass is in the form of an arch so that the building is more dynamic. The mass is made of terraces for airing and natural lighting can enter so that the utilization of renewable natural resources can be maximized.
\end{abstract}

\section{Keywords: Art hall; Ecological architecture; Ecology}

\section{PENDAHULUAN}

\section{Latar Belakang}

Perkembangan zaman tidak dapat kita pungkiri pertumbuhan dan terjadi migrasi penduduk kota dan desa berikut budaya yang dianutnya, maka hal ini yang terkadang membuat kita lupa akan pentingnya budaya, spiritual, dan pengaruhnya terhadap lingkungan dan etika kita sebagai manusia. Kota Bekasi dikenal sebagai kota patriot karena jiwa nasionalismenya yang tinggi. Selain itu Kota Bekasi juga dikenal sebagai Kota dengan kebudayaannya yang kaya. Budaya Kota Bekasi dipengaruhi oleh banyak 
suku seperti Betawi, Jawa, dan Sunda sehingga memiliki keunikannya. Namun beberapa kebudayaan daerah dari Kota Bekasi ini mengalami kepunahan. Terutama seni tari dan juga pewayangan yang merupakan salah satu media pembelajaran. Hal ini menyebabkan hilangnya identitas sebuah daerah dan hilangnya kesadaran untuk menghargai lingkungannya baik lingkungan hidup ataupun lingkungan sosial.

Pada daerah peri-urban yang merupakan wilayah yang terletak antara lahan perkotaan dan pedesaan mengalami perkembangan yang begitu cepat dampak dari pembangunan kota-kota besar yang menghimpitnya dengan perkembangan yang begitu cepat maka cepat pula pergeseran budaya yang terjadi. Seperti pada Kota Bekasi yang termasuk dari bagian kota satelit dari Ibukota Jakarta.

Semakin berkembangnya zaman, lingkungan alam pun mengalami dampak dari perkembangan ini. Seiring dengan berkembangnya zaman banyak pula kemajuan yang terjadi terutama dalam menghadapi masalah-masalah lingkungan demi mengurangi kerusakan dan dampak buruk terhadap lingkungan. Dengan begitu, kita harus menyelaraskan prilaku manusia, kemajuan yang terjadi, dan juga keseimbangan ekologi.

Kata ekologi berasal dari dua kata dari Bahasa Yunani, yaitu Oikos dan Logos. Oikos memiliki arti rumah atau tempat tinggal, sedangkan logos berarti ilmu atau pengetahuan. Menurut Ernest Haeckel (1866) Ekologi merupakan ilmu pengetahuan komprehensif tentang hubungan organisme terhadap lingkungannya. Adapun pengertian Ekologi menurut adalah ilmu yang mempelajari tentang interaksi timbal balik antara makhluk hidup dengan lingkungan sekitarnya (Soemarwoto, 1997).

Pembangunan suatu fungsi sebagai pemenuhan kebutuhan manusia haruslah mempertimbangkan lingkungan alam sekitar dan hubungan timbal balik antar manusia dan lingkungannya (Heinz \& Suskiyatno, 1998). Oleh karena itu, dalam pembangunan fungsi tersebut kita harus memperhatikan prinsip-prinsip ekologis untuk meminimalkan dampak dari bangunan tersebut kepada lingkungan.

\section{Rumusan Permasalahan}

Kota Bekasi berada diantara Kota dan desa membuat Kota Bekasi mengalami pergeseran budaya akibat perkembangan dan kemajuan dari Kota Jakarta. Kebudayaan menjadi penting karena memiliki kaitan erat dengan etika dan moral dari suatu masyarakat daerah tersebut seperti pengaruhnya terhadap lingkungan sosial dan juga lingkungan hidup. Pembangunan fungsi harus memperhatikan keseimbangan ekologi dan bagaimana penerapan prinsip-prinsipnya pada bangunan.

\section{Tujuan}

Proyek ini bertujuan sebagai pelestarian budaya kesenian tari dan pewayangan Kota Bekasi dengan memperhatikan prinsip ekologis pada bangunan. Pelestarian budaya Kota Bekasi merupakan upaya untuk memberikan wadah masyarakat Kota Bekasi untuk mengekspresikan diri dalam seni sebagai berpartisipasi dalam pelestarian kesenian Budaya Kota Bekasi.

\section{KAJIAN LITERATUR}

\section{Ekologi}

Ekologi pertama kali dkenalkan oleh Ernst Haeckel pada tahun 1866 di Jerman. Menurut Haeckel (1866) ekologi merupakan ilmu yang mempelajari hubungan antara makhluk hidup dengan lingkungannya. Ekologi merupakan ilmu yang mempelajari tentang interaksi timbal balik antara makhluk hidup dengan lingkungan sekitarnya. Ekologi membentuk sistem yang disebut ekosistem (Soemarwoto, 1997).

Ekosistem memiliki tidak hanya berisi makhluk hidup dan populasi yang berinteraksi. Ekosistem harus berisi koneksi yang interaktif antar makhluk hidup dengan benda mati pada lingkungannya (Higashi \& Burns, 1991). Ekosistem memiliki koneksi, hirarki, dan dinamika yang kompleks. Menurut Odum (1971) Ekosistem sebagai seluruh unit yang mencakup semua makhluk hidup pada suatu wilayah yang menghasilkan energi. Jonathan D. Smith (2017) seorang peneliti teologi dan agama pada risetnya mengenai agama dan gerakan sosial-environmentalis mengatakan dalam mengurangi masalah- 
masalah lingkungan tidak hanya melibatkan sains dan teknologi tetapi moral, etika dan spiritual juga berperan penting dalam hal ini (Smith, 2017).

\section{Arsitektur Ekologi}

Arsitektur ekologi merupakan perancangan berwawasan lingkungan dengan memanfaatkan potensi alam di suatu daerah tersebut secara maksimal (Heinz \& Suskiyatno, 1998). Terdapat beberapa prinsip untuk menciptakan bangunan ekologis (Heinz \& Suskiyatno, 1998): 1) Menyesuaikan dengan kondisi alam yang sebenarnya; 2) Penghematan sumber energi; 3) Memanfaatkan sumber daya alam terbarui secara maksimal; 4) Penggunaan material lokal; 5) Menggunakan teknologi untuk mencapai bangunan yang hemat energi; 6) Meminimalkan dampak pada lingkungan.

\section{Melampaui Ekologi dalam Arsitektur}

Melampaui ekologi merupakan kondisi dimana ekosistem dan kondisi sosialnya mengalami percepatan dan kecepatan (Agustinus, 2021). Kecepatan ini dan percepatan akan terus terjadi pekembangan teknologi pun akan terus terjadi dan dampak yang dihasilkan pada lingkungan pun semakin bertambah. Dampak yang terjadi dari percepatan yang terjadi yaitu kerusakan lingkungan. Untuk meminimkan kerusakan alam yang terjadi, melampaui ekologi salah satu cara untuk mengurangi kerusakan yang terjadi pada lingkungan. Arsitektur memiliki parameter sebagai berikut untuk melampaui ekologi (Agustinus, 2021): 1. Energi dan emisi (menerapkan zero $\mathrm{CO}_{2}$ pada penggunaan material dan konstruksi); 2. Adaptasi (Mendesain dengan memperhatikan dampaknya terhadap lingkungan); 3. Resiliensi (mendesain dengan memperhatikan ketahanan bangunan terhadap bencana alam); 4. Kelanjutan digital (menentukan strategi dengan memperhatikan data lingkungan); 5. Teknologi Baru (memanfaatkan teknologi baru); 6. Kontekstual (memperhatikan lingkungan dan hubungan antara lingkungan dengan ruangan yang akan ditempatkan).

\section{Kesenian Tari}

Seni merupakan penjelmaan rasa indah yang terkandung dalam jiwa seseorang, dilahirkan dengan perantara alat komunikasi dalam bentuk yang dapat ditangkap indera pengelihatan (Seni luki), pendengaran (Seni musik), dan gerakan (Seni tari) (Bastomi, 1988). Sedangkan pengertian seni tari merupakan anggota tubuh yang digerakan yang kemudian disusun selaras dengan irama musik, serta mempunyai maksud tertentu (Mulyani, 2016). Jenis Seni tari terbagi menjadi dua yaitu (Hidajat, 2005): 1) Seni Tradisional yiatu seni tari yang telah mengandung nilai-nilai masa lampau dan dipertahankan sehingga memiliki hubungan ritual dan adat istiadat; 2) Seni tari modern terdiri dari tari Hip-hop, Breakdance, Freestyle, street dance, robot dance, crip walk, ballroom dance, concert dance, dan moonwalk dance.

\section{Kesenian Tari Kota Bekasi}

Kesenian Bekasi banyak dipengaruhi oleh budaya Banten, Jawa Barat, Jawa Tengah, dan Jawa Timur. Kesenian tari di Kota Bekasi meliputi (Sopandi, 2009): 1) Tari Topeng yaitu seni tari yang mengkombinasikan pencak silat, lawak, dan tarian; 2) Tari Dodogeran yaitu tarian yang mencerminkan keceriaan anak-anak dengan percampuran budaya Betawi dan Sunda; 3) Tari Kembang yang merupakan percampuran budaya Betawi, Cina, dan Sunda.

\section{Wayang Kulit Kota Bekasi}

Wayang memiliki arti bayangan yang mempertunjukan suatu lakon yang diceritakan oleh dalang, sedangkan kulit memiliki arti bahan yang digunakan yaitu kulit hewan (Puspitasari, 2008). Kesenian wayang kulit pada Kota Bekasi merupakan pengaruh dari budaya Jawa Tengah, walaupun penyebaran wayang telah terjadi di daerah Jawa Barat, Jawa Tengah dan Jawa Timur tetapi setiap daerah memiliki ciri khasnya. Perbedaan wayang kulit Kota Bekasi yaitu: 1) Dialek yang digunakan saat pertunjukan yaitu dialek Bekasi; 2) Alat yang digunakan merupakan alat sederhana; 3) Komunikasi dengan penonton yang sangat erat (Sopandi, 2009). 


\section{METODE}

Metode yang digunakan dalam penelitian dengan menggunakan metode penelitian kualitatif dengan pengumpulan data literatur dan analisis tapak. Metode perancangan yang digunakan merupakan prinsip teori ekologis menurut Heinz Frick (2007). Berdasarkan prinsip arsitektur ekologis pada bangunan yaitu: 1) sustainability; 2) Kontekstual; 3) Adaptasi (penyesuaian terhadap kondisi lingkungan); 4) Resiliensi (adaptasi dari kondisi lingkungan). Prinsip ekologis diaplikasikan dalam perancangan bangunan.

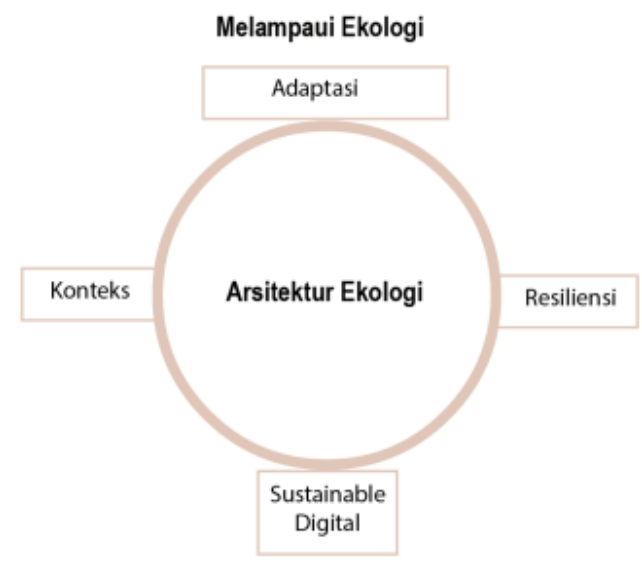

Gambar 1. Metode Perancangan

Sumber: Penulis, 2021

\section{DISKUSI DAN HASIL}

\section{Tapak}

Tapak berlokasi pada Jalan Ahmad Yani, Bekasi Selatan, Kota Bekasi. Berada di jalan arteri primer. berada di kawasan pariwisata dan Pusat Pemerintahan Kota Bekasi. Memilki jarak $300 \mathrm{~m}$ menuju Stadion Bekasi dan Taman Kota Bekasi, 700 m menuju Stasiun Kota Bekasi, dan 100 m menuju halte bus. Tapak berorientasi pada barat dan pada barat laut terdapat Stadion Bekasi. Tapak berada pada zona campuran. Memiliki KDB 50\%, KLB 20, KDH 30\%, KB 43 yang berarti tapak berada pada kawasan bangunan tinggi dan padat. Pada timur tapak tepatnya pada bagian belakang tapak terdapat kali irigasi Bekasi dan jalan satu arah dengan lebar jalan $5 \mathrm{~m}$.

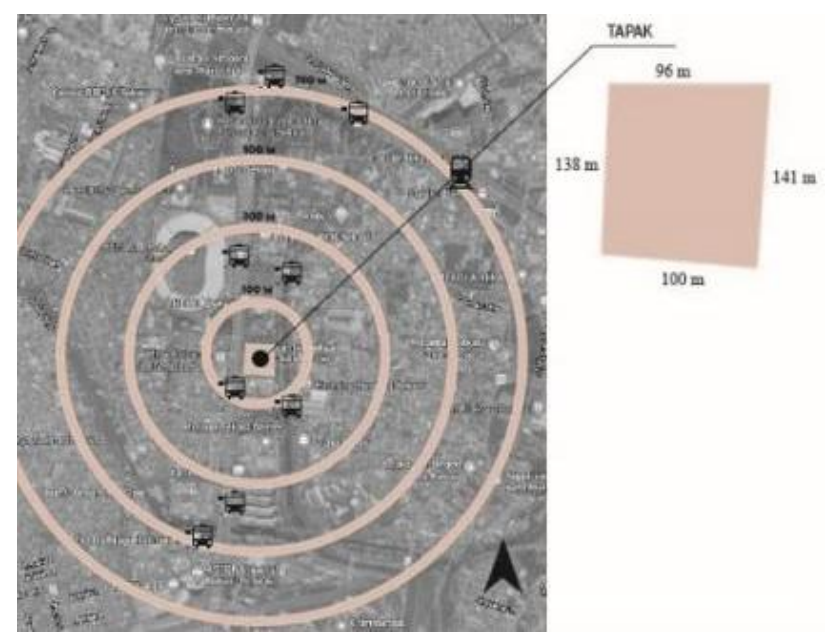

Gambar 2. Tapak

Sumber: Penulis, 2021 


\section{Zoning}

Zoning terdiri dari publik, semi publik, kolam retensi, dan parkir. Zona publik merupakan tempat pertunjukan memiliki sifat terbuka untuk umum. Pada zona semi publik merupakat fasilitas kelas tari, kantor, galeri yang dapat dikunjungi dengan kepentingan tertentu. Zona parkir berada di belakang bangunan agar tidak mengganggu view dari bangunan. Kolam retensi berdekatan dengan kali irigasi Bekasi. Kolam retensi sebagai penyerapan hujan dan pengendalian terhadap banjir pada tapak.

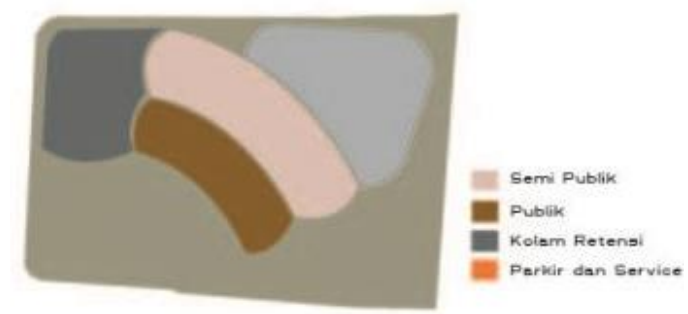

Gambar 3. Zoning

Sumber: Penulis, 2021

\section{Konsep}

Konsep yang digunakan pada bangunan adalah Net Zero Source Energy Building (Source ZEB) yaitu dimana bangunan menghasilkan energi sebanyak energi yang digunakan bangunan itu sendiri. Sumber energi yang digunakan pada bangunan merupakan energi matahari dengan penggunaan panel surya serta pengolahan kembali air kotor untuk keperluan air bangunan (Grey water recycling). Prinsip dari konsep ini yaitu meminimalkan penggunaan energi dan memaksimalkan penggunaan sumber daya alam terbarukan.

\section{Massa}

Gubahan massa berorientasi pada barat laut menuju Stadion bekasi agar tercipta konektivitas antara Stadion Bekasi, Taman bekasi dan bangunan. Gubahan massa dibentuk melengkung agar sinar matahari tidak masuk secara langsung. Massa diangkat sebagai penanggulangan banjir sehingga pada lantai dasar hanya digunakan untuk parkir mobil dan service. Massa dibuat berundak agar pencahayaan dan pengudaraan alami dapat masuk.

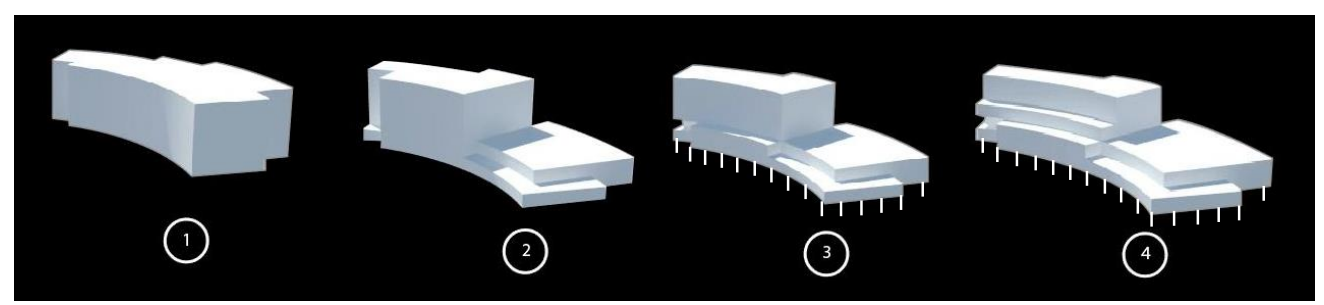

Gambar 4. Gubahan Massa

Sumber: Penulis, 2021

\section{Program}

Program pada proyek merupakan program yang berperan sebagai wadah pelestarian kesenian tari tradisional dan modern Kota Bekasi selain itu juga pewayangan kulit Kota Bekasi. Program yang diadakan yaitu kelas tari sebagai pewadahan kreativitas dan upaya pelestarian, ruang pertunjukan seni sebagai upaya pengapreasian seni sehingga nilai-nilai budaya dan nilai-nilai moral yang terkandung dalam sebuah seni tari dan juga seni pewayangan dapat tersampaikan.

Program yang dimunculkan pada bangunan yaitu 1) Program utama yang terdiri dari ruang pertunjukan luar, kelas tari, galeri wayang, auditorium, workshop, dan ruang baca; 2) Program penunjang terdiri dari coffee shop, kantor pengelola, dan ruang service. Berikut presentasi program pada bangunan: 


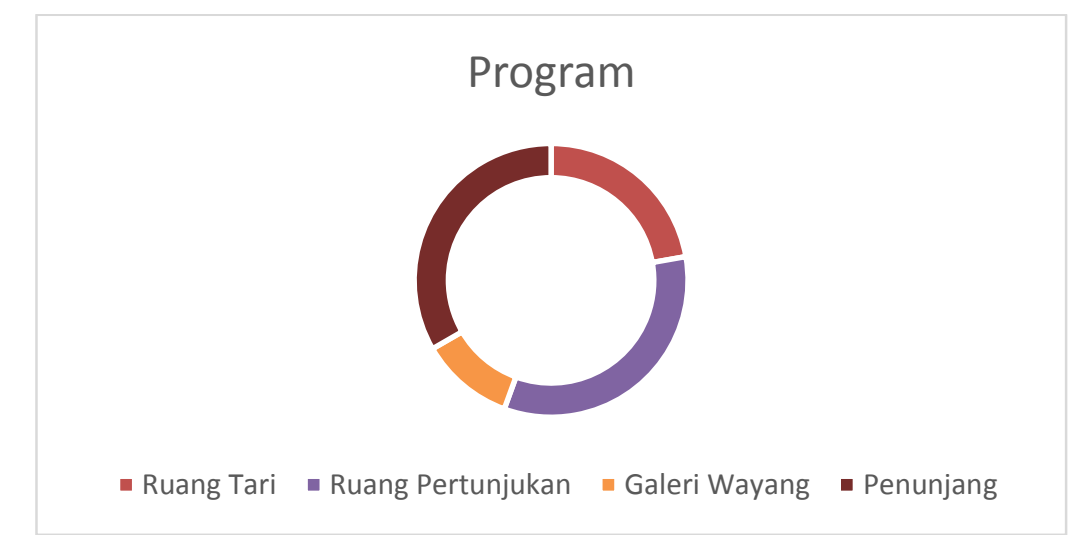

Gambar 5. Program Ruang

Sumber: Penulis, 2021

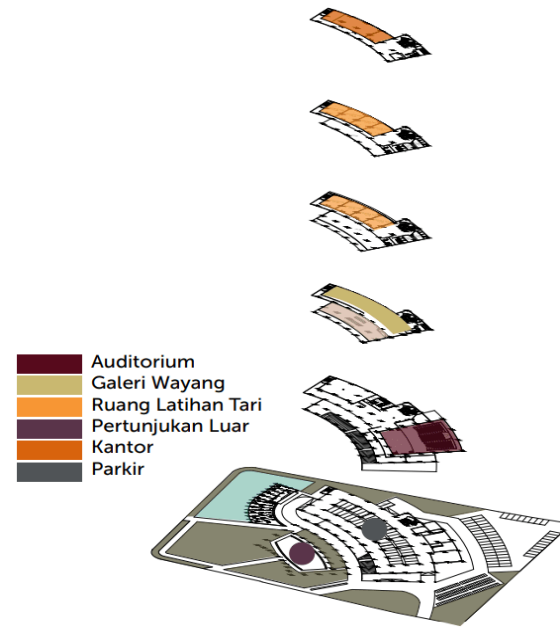

Gambar 6. Zoning Vertikal

Sumber: Penulis, 2021

Pelaku dari aktivitas program diatas merupakan anak-anak, remaja dan orang dewasa sebagai pengguna utama dan pengapresiasi seni. Kesenian tari yang dipraktikan yaitu tari tradisional (Tari Topeng, Tari Dodogeran, Tari Kembang, dan Tari Ronggeng) dan modern (Hip-hop, Street dance, Robot dance, Ballroom dance) dengan kebutuhan ruang gerak perorang $3 \mathrm{~m}^{2}$ dan pelaku terdiri dari solo, duet, dan kelompok. Pada kelas tari kapasitas perkelas terdiri dari 20 orang dengan ukuran kelas $9 \times 10$ m pelaku.

Auditorium memiliki kapasitas pengunjung 300 orang dengan panggung berukuran $9 \times 24 \mathrm{~m}$ untuk pertunjukan seni tari tradisional dan modern, workshop memiliki kapasitas pengunjung sebanyak 80 orang serta ruang pertunjukan luar yang digunakan sebagai ruang pertunjukan wayang dengan luas $1686 \mathrm{~m}^{2}$ memiliki kapasitas 100 orang. Area pertunjukan wayang digunakan oleh para pengiring musik (gendang, gamelan, rebab, bonang, dan lainnya), satu dalang dengan alat perlengkapan (wayang, kelir, gedhog, dan keprak), dan penonton.

\section{Tata Ruang dan Sirkulasi}

Sirkulasi pada bangunan dibagi menjadi sirkulasi jalan utama dan sirkulasi jalur pedestrian. Jalur utama digunakan oleh kendaraan yang berasal dari Jalan Ahmad Yani. Jalur masuk kendaraan memiliki jalur yang berbeda. Setelah masuk menuju tapak terdapat dua tempat parkir berbeda yaitu parkir yang berada pada bawah bangunan dan juga parkir yang berada di luar bangunan. Jalur keluar pada tapak keluar menuju Jalan Ahmad Yani. 


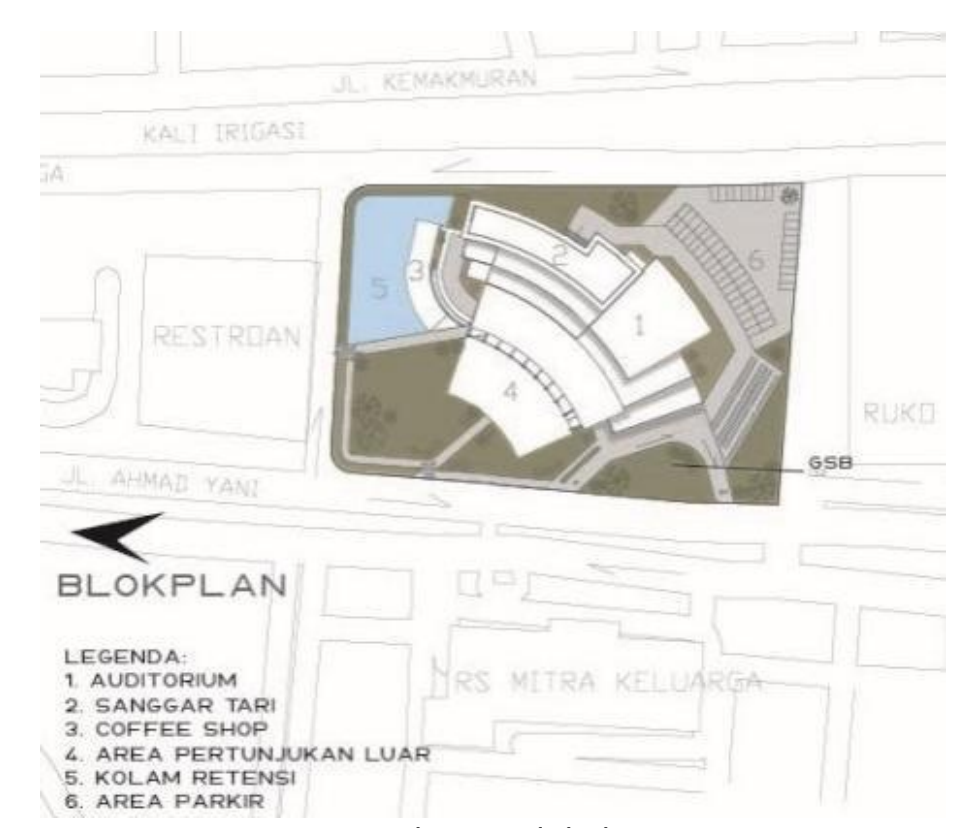

Gambar 7. Blokplan

Sumber: Penulis, 2021

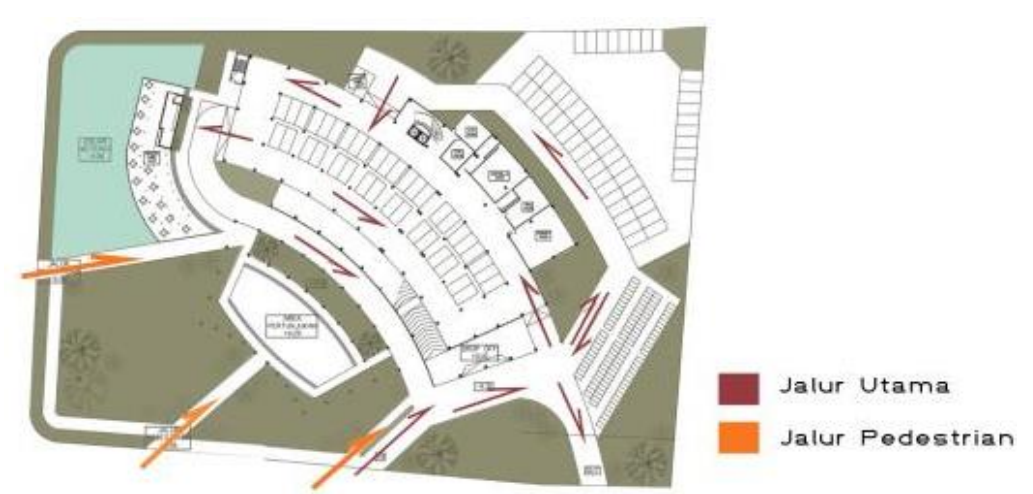

Gambar 8. Siteplan

Sumber: Penulis, 2021

Lantai dasar digunakan sebagai pertunjukan luar, coffee shop, service dan tempat parkir. Akses menuju lantai 2 dimana merupakan tempat auditorium, dan ruang workshop dapat melalui ramp yang berada pada depan bangunan serta akses melalui lift dan tangga yang berada pada bagian dalam bangunan.

Pada lantai 3 terdapat galeri wayang dan ruang baca. Pada ruang baca memiliki secondary skin yang dapat diatur dengan diputar sehingga dapat mengatur berapa banyak sinar matahari yang masuk. Lantai 3 hingga lantai 6 dapat di akses dengan tangga dan lift. 


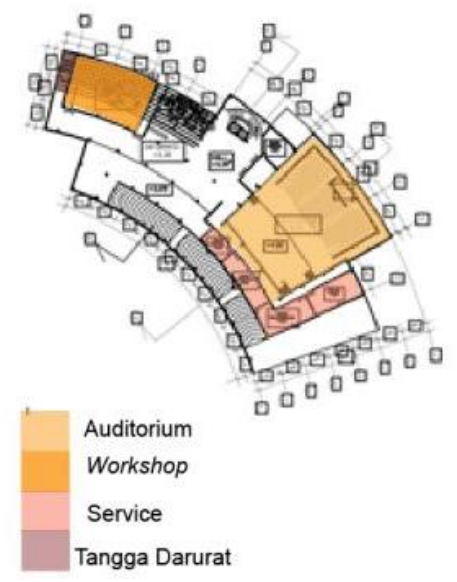

Gambar 9. Denah Lantai 2

Sumber: Penulis, 2021

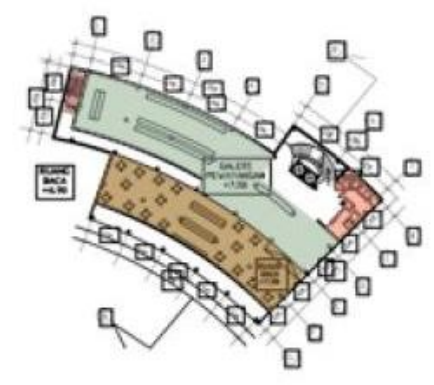

Galeri Wayang

Ruang Baca

Service

Tangga Darurat

Gambar 10. Denah Lantai 3

Sumber: Penulis, 2021

Pada lantai 4 dan 5 merupakan tempat kelas tari. Pada lantai 4 ruang latihan terdapat pada kelas-kelas dan juga ruang latihan luar yang berada pada selasar bangunan. Penghawaan dan pencahayaan ruang latihan luar pada lantai 4 merupakan pengudaraan dan pencahayaan alami karena merupakan ruang semi-outdoor.

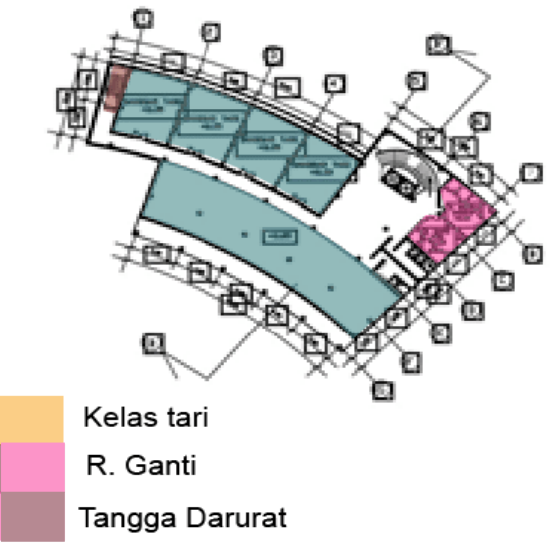

Gambar 11. Denah Lantai 4 Sumber: Penulis, 2021

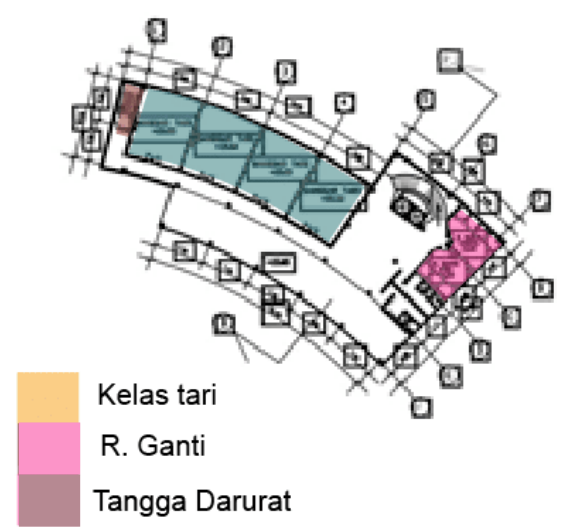

Gambar 12. Denah Lantai 5 Sumber: Penulis, 2021

Pada lantai 6 terdapat kantor terdiri dari kantor pengelola dan ruang meeting serta pantry dan toilet. Pada denah atap terdapat panel surya sebagai sumber energi bangunan. Untuk menuju lantai ini dapat diakses melalui tangga darurat.

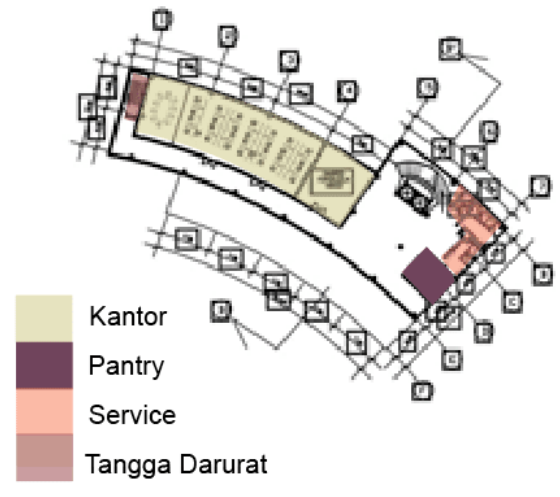

Gambar 13. Denah Lantai 6 Sumber: Penulis, 2021

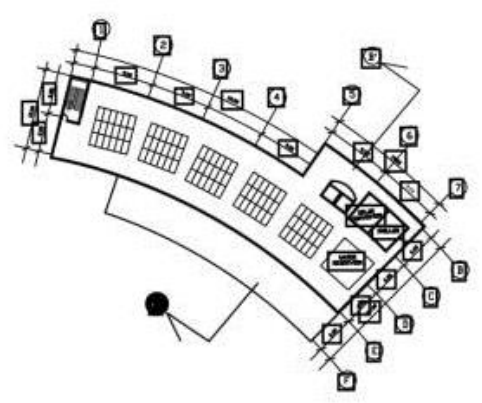

Gambar 14. Denah Atap

Sumber: Penulis, 2021 


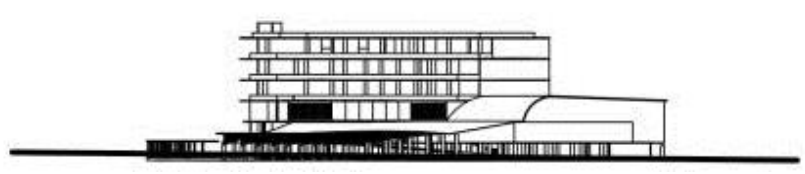

Gambar 15. Tampak Depan

Sumber: Penulis, 2021

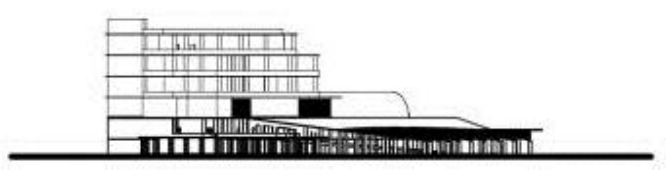

Gambar 16. Tampak Kiri

Sumber: Penulis, 2021

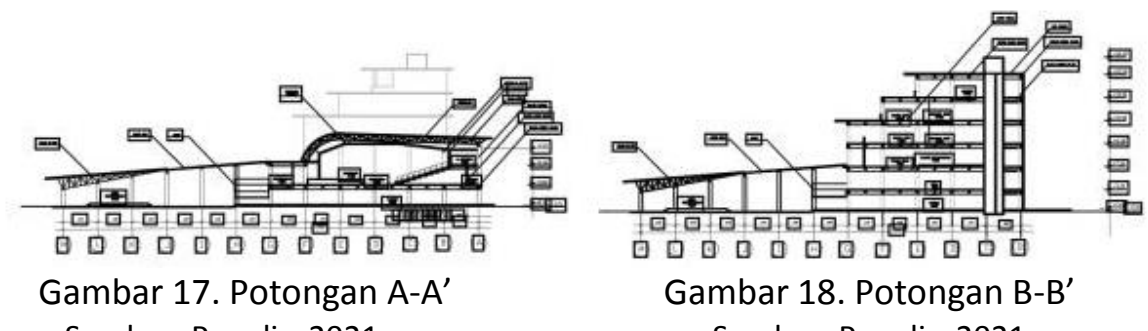

Sumber: Penulis, 2021

Sumber: Penulis, 2021

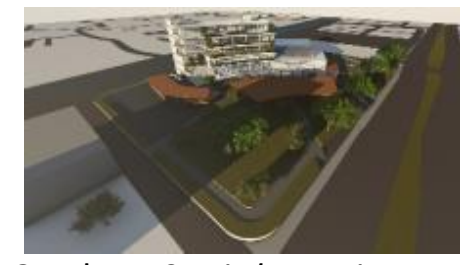

Gambar 19. Bird-eye view Sumber: Penulis, 2021

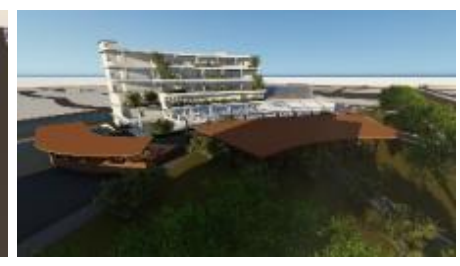

Gambar 20. Eksterior Sumber: Penulis, 2021

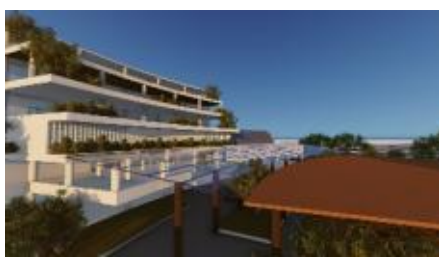

Gambar 21. Eksterior Sumber: Penulis, 2021

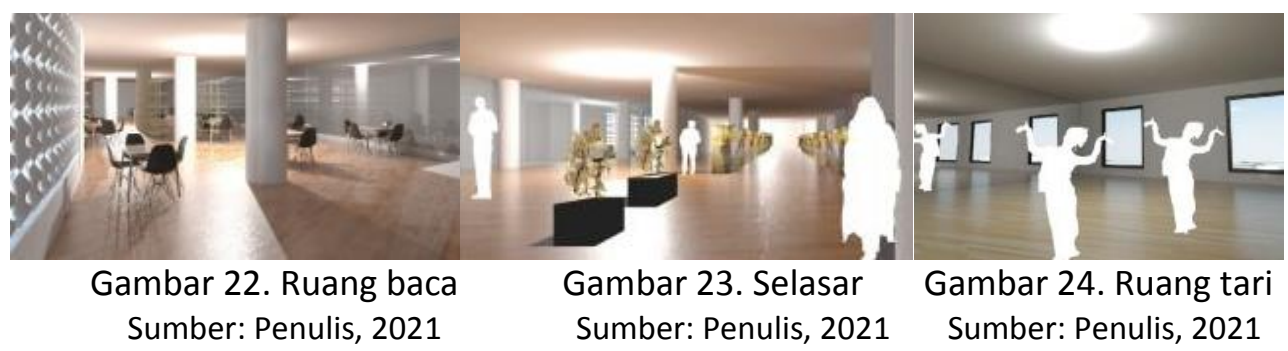

\section{Struktur dan Material}

Struktur utama yang digunakan pada bangunan merupakan struktur rangka atau rangka beton bertulang. Lebar bentang bangunan yaitu $6 \times 9 \mathrm{~m}$ dengan besar balok $40 / 80 \mathrm{~cm}$. Kolom pada bangunan memiliki diameter sebesar $60 \mathrm{~cm}$.

Auditorium menggunakan stuktur bentang lebar dengan rangka atap yaitu rangka batang. Material yang digunakan sebagai rangka yaitu baja. Pada atap bangunan sanggar tari menggunakan dak beton dengan ketebalan $20 \mathrm{~cm}$. Pada atap ini akan dipasang panel surya sebagai sumber energi bangunan. 


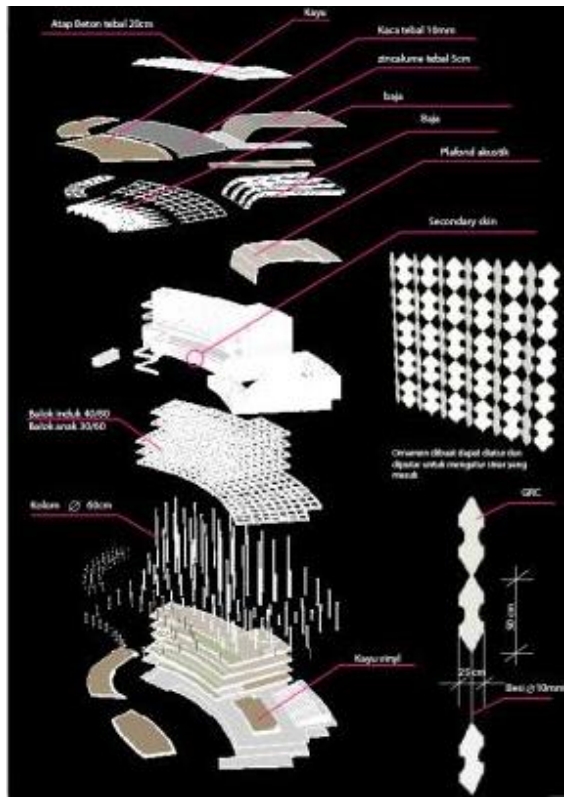

Gambar 25. Struktur

Sumber: Penulis, 2021

Material yang digunakan pada penutup atap area pertunjukan ruang luar merupakan kayu ulin dan baja untuk rangka struktur. Penutup atap pada auditorium menggunakan material zincalume karena flesibilitasnya sehingga dapat dibentuk sesuai rangka. Penutup atap sanggar tari menggunakan beton. Penggunaan secondary-skin menggunakan material GRC.

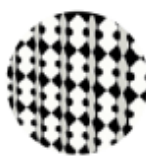

GRC

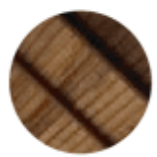

KAYU ULIN

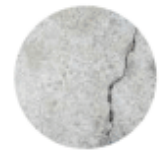

BETON

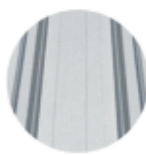

ZINCALUME

Gambar 26. Material

Sumber: Penulis, 2021

\section{Utilitas}

\section{Sistem plumbing}

Sistem air bersih yang digunakan merupakan sistem zero run-off dengan mengolah kembali air yang telah digunakan (grey-water recylcing) untuk pengairan vegetasi pada tapak dan juga air toilet.

Air hujan ditampung pada kolam retensi lalu digunakan dan diolah kembali pada bangunan. Air hujan dialirkan melalui pipa menuju kolam retensi.

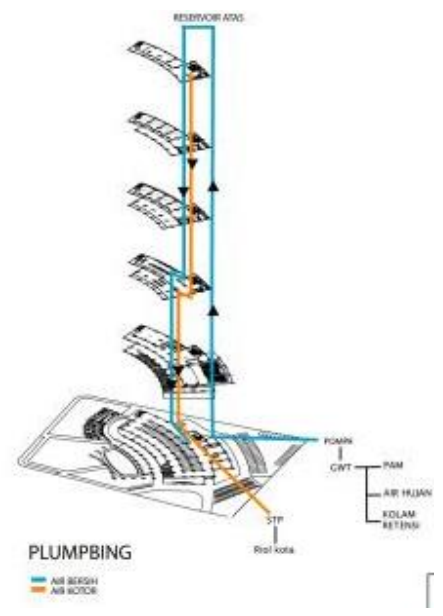


Gambar 27. Sistem Plumbing

Sumber: Penulis, 2021

\section{Sistem Elektrikal}

Sumber listrik utama pada bangunan berasal dari panel surya. Untuk listrik cadangan diperlukan baterai untuk menyimpan listrik dari panel. Panel surya yang dibutuhkan untuk memenuhi kebutuhan listrik bangunan yaitu 7 dengan kekuatan 280 watt dengan besar panel surya $1 \times 1.96 \mathrm{~m}$.

Listrik yang dibutuhkan per hari:

Tabel 1. Penggunaan energi bangunan

\begin{tabular}{|c|c|c|}
\hline Alat & Jumlah & Energi (Watt) \\
\hline AC & 17 buah & 42.690 \\
\hline Lampu & 199 buah & 3.980 \\
\hline AC central & 1 & 3.500 \\
\hline Speaker & 6 & 2.700 \\
\hline Kulkas & 1 & 160 \\
\hline Pompa air & 1 & 500 \\
\hline Lift & 2 & 4000 \\
\hline Penggunaan lainnya & $20 \%$ & 11.760 \\
\hline Total & \multicolumn{2}{|l}{} \\
\hline
\end{tabular}

Sumber: Penulis, 2021

Bangunan beroperasi 12 jam perharinya sehingga bangunan membutuhkan energi sebanyak $846 \mathrm{Kw}$. Panel surya dapat menghasilkan energi sebanyak $16.800 \mathrm{~W}$ dalam 1 jam. Panel surya kapasitas 280 watt digunakan 8 jam perharinya sehingga 1 panel surya dapat menghasilkan $134 \mathrm{Kw}$ per harinya. Maka panel surya yang dibutuhkan:

Panel surya $=$ energi perhari : energi dihasilkan panel surya

$$
\begin{aligned}
& =846 \mathrm{Kw}: 134 \mathrm{Kw} \\
& =6,3=7 \text { Panel surya }
\end{aligned}
$$

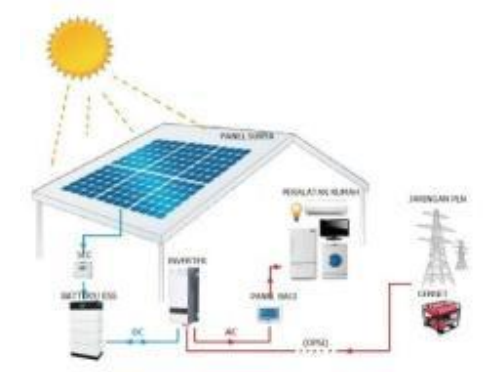

Gambar 28. Skema Panel Surya

Sumber: Sunergi.co.id, 2021

Pada musim hujan energi pada sinar matahari akan disimpan pada baterai dan disalurkan ketika dibutuhkan. Jika energi yang dihasilkan dari sinar matahari tidak mampu mencukupi kebutuhan bangunan pada saat musim hujan bangunan akan menerima energi dari PLN.

\section{Pengudaraan}

Sistem pengudaraan pada bangunan dibagi menjadi 2 pengudaraan buatan dan alami. Pengudaraan buatan terdiri dari AC split yang diletakan pada kelas-kelas, kantor dan galeri wayang sementara AC central digunakan pada ruangan auditorium.

\section{KESIMPULAN DAN SARAN Kesimpulan}

Perancangan balai budaya kesenian tari dan pewayangan merupakan upaya pelestarian budaya Kota Bekasi. Prinsip arsitektur ekologi merupakan salah satu cara agar dampak dari bangunan dan 
manusianya terhadap lingkungan dapat di minimalisir. Penerapan konsep Source ZEB digunakan untuk meminimalkan penggunaan energi dengan menggunakan sinar matahari sebagai sumber energi. Konsep ini juga menggunakan prinsip dimana bangunan harus memaksimalkan pengggunaan sumber daya alam terbarui seperti angin, sinar matahari. Penerapan prinsip arsitektur ekologi dimunculkan pada massa bangunan dan pada sistem utilitas bangunan. Massa bangunan dibentuk melalui analisis tapak sehingga bangunan dapat beradaptasi dengan lingkungan.

Budaya yang dilestarikan pada bangunan yaitu kesenian tari tradisional dan modern (Hip-hop, Street dance, Robot dance, Ballroom dance) serta wayang kulit. Ruang yang disediakan sebagai wadah pelestarian kesenian tari dan wayang kulit yaitu auditorium dengan kapasitas penonton 300 orang, ruang latihan tari dengan kapasitas 20 orang dan memiliki luas kelas $90 \mathrm{~m}^{2}$, pertunjukan ruang luar sebagai tempat pertunjukan wayang kulit yang memiliki kapasitas 100 orang, galeri wayang dengan besar ruangan $600 \mathrm{~m}^{2}$, ruang baca, dan ruang workshop dengan kapasitas 80 orang. Lantai 4,5 , dan 6 yang merupakan kelas tari dan kantor dibuat menjadi ruangan semi-outdoor untuk memaksimalkan pengudaraan alami selain itu agar setiap kelas dapat memiliki jendela dan ventilasi agar udara dapat bersirkulasi dengan baik. Penerapan prinsip ekologis juga diterapkan pada utilitas bangunan seperti penerapan sistem Zero run-off dengan memanfaatkan air kotor dan air hujan yang diolah kembali (grey-water recylcing).

\section{Saran}

Hasil perancangan balai budaya seni tari dan pewayangan masih banyak kekurangan. Pada perancangan gedung kesenian penerapan prinsip arsitektur ekologi dan konsep Souce ZEB masih perlu peninjauan lebih jauh dalam hal perhitungan penggunaan energi dan penyediaan sumber energi dengan menggunakan sumber energi matahari (Panel surya).

\section{REFERENSI}

Bastomi, S. (1988). Apresiasi Kesenian Tradisional. Semarang: IKIP Semarang.

Effendi, R., Salsabila, H., \& Malik, A. (2018). Pemahaman Tentang Lingkungan dan berkelanjutan. 76. Heinz, F., \& Suskiyatno. (1998). Dasar-dasar Eko-arsitektur. Semarang: Penerbit Kanisius. Hidajat, R. (2005). Wawasan Seni: Tari Pengetahuan Praktis bagi Guru Seni Tari Malang. Higashi, \& Burns. (1991). Theoritical Studies of Ecosystems The Network Perspective. Mulyani, N. (2016). Pendidikan Seni Tari Anak Usia Dini. Yogyakarta: Gava Media.

Odum , E. (1971). Fundamental of Ecology. Philadelphia: W.B. Saunders Company.

Puspitasari, M. (2008). Wayang Kulit sebagai Media Penyebaran Agama Islam. Universitas Sebelas Maret.

Smith, J. (2017). Connecting Global and Local Indonesian religious Environmental Movements Through Spatial Analysis.

Soemarwoto, O. (1997). Ekologi, Lingkungan Hidup dan Pembangunan. Jakarta: Djambatan. Sopandi, A. (2009). Sejarah dan Budaya Kota Bekasi. Retrieved from Dinas pemuda Olahraga, Kebudayaan, dan kepariwisataan.

Sutanto, A. (2021). Dromos Oikos. Jakarta. 